\title{
Caso radiológico para diagnóstico
}

Drs. José A. de Grazia $\mathrm{K}^{(1,2)}$, Marcelo Godoy $Z^{(1,2)}$, Tomás Cermenati $\mathrm{B}^{(1,2)}$, Francisca Araya $\mathrm{C}^{(1,2)}$, Claudio Cortés $\mathrm{A}^{(1)}$.

1. Centro de Imagenología, Hospital Clínico Universidad de Chile, Santiago - Chile.

2. Médico Becario de Radiología.

Historia clínica

Paciente hombre de 55 años con antecedentes de tabaquismo suspendido. Consulta por cuadro de dos meses de evolución de dolor abdominal epigástrico, vómitos y diarrea intermitentes y baja de peso de $15 \mathrm{Kg}$. La endoscopía digestiva alta muestra pliegues gástricos engrosados de consistencia elástica, más prominentes a nivel del fondo y cuerpo, con algunas erosiones superficiales. En los exámenes de laboratorio se pesquisa hipoalbuminemia. Se realiza estudio baritado esófago-estómago-duodeno (Figura 1).

\section{¿Cuál es su diagnóstico?}

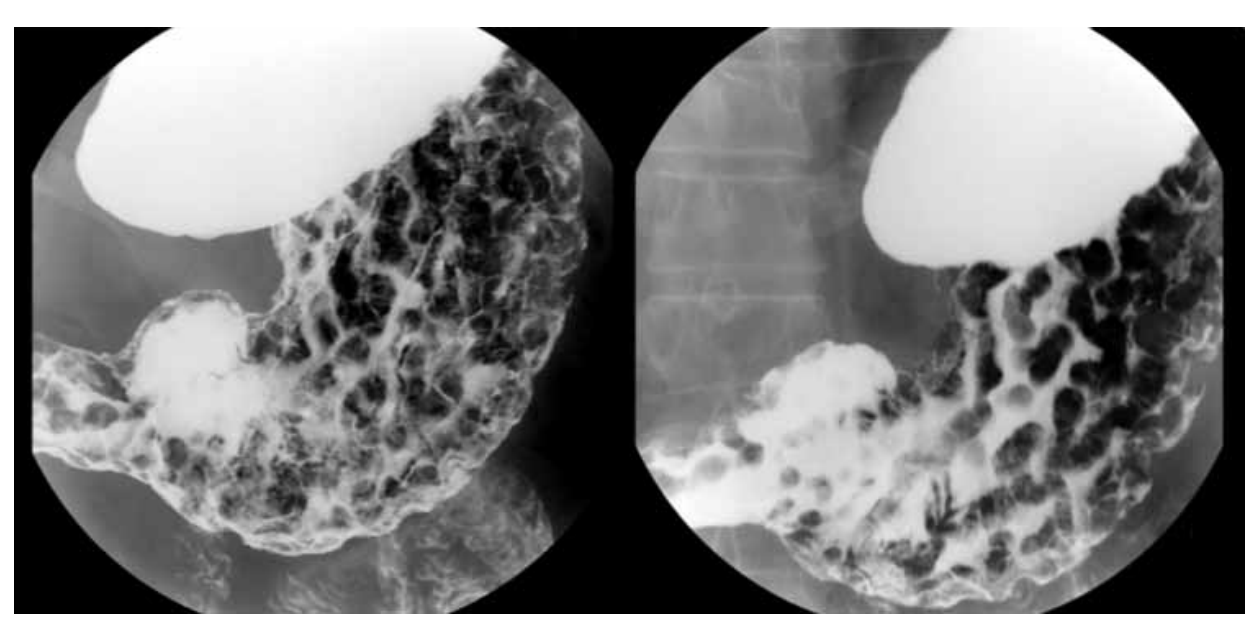

Figura 1. 


\section{Resultado caso radiológico para diagnóstico}

Drs. José A. de Grazia $K^{(1,2)}$, Marcelo Godoy $Z^{(1,2)}$, Tomás Cermenati $B^{(1,2)}$, Francisca Araya $C^{(1,2)}$, Claudio Cortés $A^{(1)}$.

1. Centro de Imagenología, Hospital Clínico Universidad de Chile, Santiago - Chile.

2. Médico Becario de Radiología.

viene de la página 96.

Diagnóstico:

Enfermedad de Ménétrier

Resultado

El estudio baritado esófago-estómago-duodeno (Figura 1) demuestra la presencia de pliegues gástricos engrosados y tortuosos, con mantención de la elasticidad de éstos ante la compresión. Se realiza además una enteroclisis por tomografía computada (Figura 2) que confirma la presencia de engrosamiento parietal gástrico difuso, con pliegues gástricos prominentes y aumento de la captación de medio de contraste en la mucosa, sin evidenciarse hallazgos patológicos en el intestino delgado. Finalmente, una endosonografía gástrica realizada con equipo radial de 7,5 MHz (Figura 3) permite objetivar pliegues gástricos engrosados hasta $13 \mathrm{~mm}$ a expensas de la segunda capa, principalmente muscular de la mucosa, con algunas áreas hipoecogénicas de aspecto quístico.

El análisis histológico de las muestras de mucosa gástrica obtenidas en la endoscopía digestiva alta confirman la presencia de hiperplasia foveolar difusa, asociada a atrofia glandular, con numerosas células mucinosas y dilatación quística, además de un infiltrado inflamatorio escaso de predominio linfoplasmocitario en la lámina propia.

Los hallazgos imagenológicos, junto con la confirmación histológica, ponen en evidencia una enfermedad

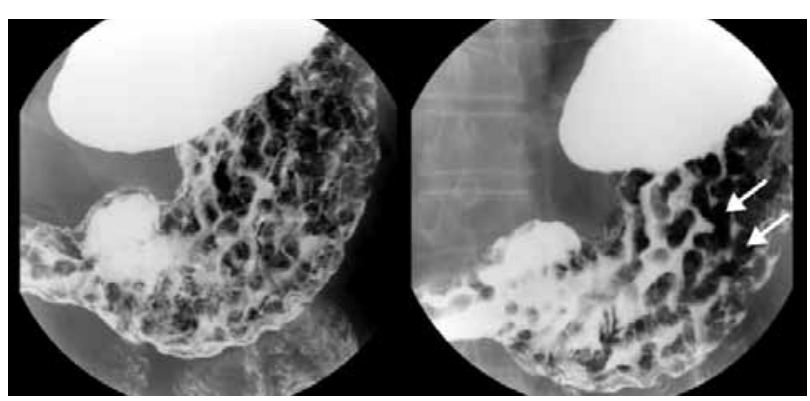

Figura 1. Estudio baritado esófago-estómago-duodeno en paciente con enfermedad de Ménétrier. Se observan pliegues gástricos severamente engrosados y tortuosos, más prominentes a nivel de la curvatura mayor de fondo y cuerpo (flechas blancas)

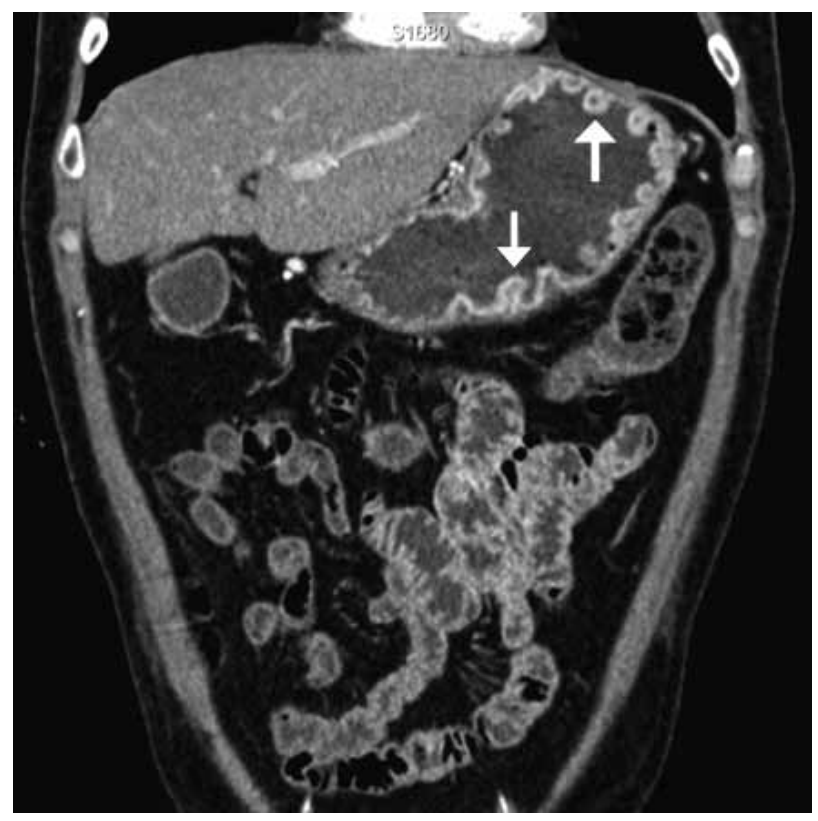

Figura 2. Enteroclisis por TC, reconstrucción coronal, en paciente con enfermedad de Ménétrier. Se observa engrosamiento parietal gástrico difuso, con pliegues prominentes y aumento de la captación de medio de contraste en la mucosa (flechas blancas).
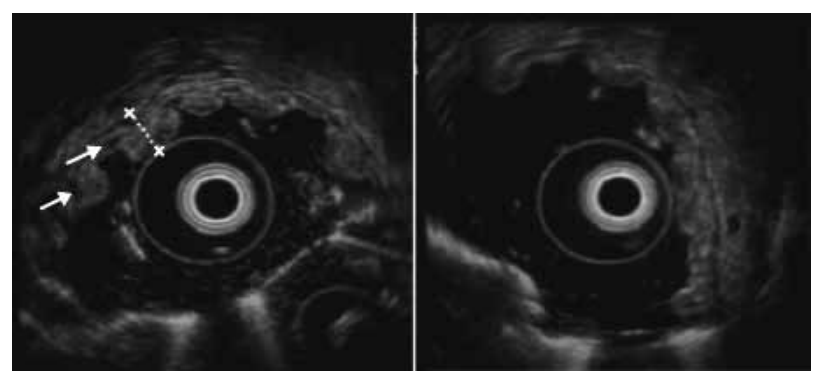

Figura 3. Endosonografía gástrica en paciente con enfermedad de Ménétrier. Se observan pliegues gástricos engrosados (distancia entre los caliper $=13 \mathrm{~mm}$ ), a expensas de la segunda capa, principalmente muscular de la mucosa, con algunas áreas hipoecogénicas de aspecto quístico (flechas blancas). 
de Ménétrier. Debido a la severidad del caso, dado por la gran baja de peso y la pérdida persistente de proteínas, se decide realizar una gastrectomía total. El estudio anatomopatológico de la pieza quirúrgica (Figura 4) resulta concordante con el diagnóstico preoperatorio. Discusión

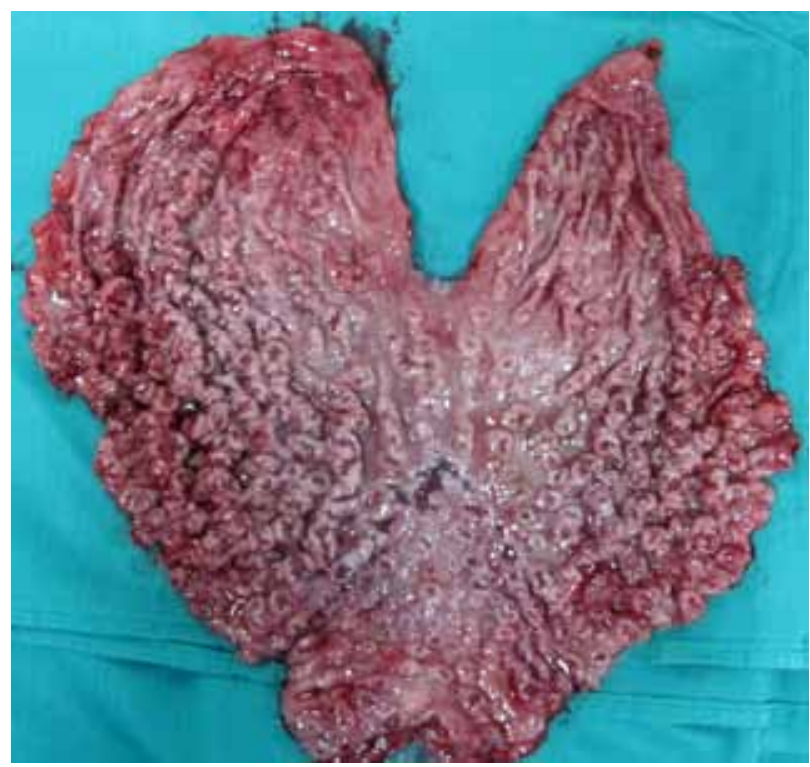

Figura 4. Pieza quirúrgica de estómago en paciente con enfermedad de Ménétrier. Se observa el estómago abierto por la curvatura mayor, con la pared engrosada en forma difusa y la mucosa con pliegues engrosados, congestivos, algunos con erosión superficial.

La enfermedad de Ménétrier es una enfermedad poco frecuente, con una prevalencia menor a 1 en 200.000 habitantes ${ }^{(1)}$. Su característica principal es la hipertrofia de los pliegues gástricos en forma difusa, preferentemente a nivel del cuerpo y fondo ${ }^{(2)}$. Para su diagnóstico es necesario conjugar datos clínicos, endoscópicos, radiológicos y anátomo-patológicos.

La sintomatología incluye dolor abdominal epigástrico, náuseas, vómitos, diarrea, anemia, baja de peso y edema periférico por hipoproteinemia ${ }^{(2,3)}$. Pareciera ser más frecuente en hombres, con un promedio de edad de 55 años. Se han descrito casos en niños, pero con resolución espontánea y relacionados a infección por citomegalovirus ${ }^{(3,4)}$.

La endoscopía digestiva alta demuestra una mucosa gástrica irregular e hipertrófica, con pliegues que semejan circunvoluciones cerebrales ${ }^{(1)}$. La endosonografía demuestra un engrosamiento de los pliegues gástricos mayor o igual a $13 \mathrm{~mm}$, a expensas de la mucosa (sgunda capa ultrasonográfica del estómago), con ecogenicidad aumentada, mientras que la submucosa y muscular propia (tercera y cuarta capa respectivamente) aparecen respetadas $s^{(1,5)}$.

Con respecto a la apariencia en los estudios baritados, se observa engrosamiento de pliegues gástricos, los cuales son rugosos y tortuosos, con distensibilidad conservada. Puede comprometer todo el estómago, pero es más marcado en la curvatura mayor, a nivel de cuerpo y fondo. El bario queda atrapado en las criptas entre los pliegues y desarrolla líneas espiculadas perpendiculares al eje del estómago ${ }^{(1,6)}$.

En tomografía computada se puede encontrar distorsión de la mucosa gástrica, que se proyecta hacia el lumen y presenta aumento de captación del medio de contraste, con la pared gástrica entre los pliegues conservada o levemente engrosada y el contorno seroso liso ${ }^{(1,7)}$. La tomografía computada ha demostrado ser útil en el diagnóstico diferencial de pliegues gástricos engrosados al valorar no sólo la superficie sino también el grosor de la pared, siendo la pérdida de la estratificación de la pared un factor predictor de malignidad ${ }^{(7)}$.

En la anatomía patológica se describe engrosamiento de la mucosa causado por hiperplasia de las células epiteliales, criptas glandulares profundas (foveolas) y dilataciones quísticas que ensanchan los pliegues gástricos (compuestos de un core submucoso y mucosa engrosada). La muscular de la mucosa aparece desordenada y engrosada, con líneas de muscular protruyendo sobre la lámina propia hacia los pliegues. Existe un aumento en las células secretoras de mucina y disminución de las células parietales, que se correlaciona con la menor secreción de ácido clorhídrico. Puede existir una cantidad no relevante de infiltrado linfoplasmocitario en la submucosa ${ }^{(1-3)}$.

Con respecto a la etiología, se conoce que una sobreexposición al factor de crecimiento de tejidos alfa (TGF- $\alpha$ ) causa en ratones una alteración similar a la enfermedad de Ménétrier, siendo esta exposición dosis dependiente. La causa de esta sobreexpresión aún no se conoce y se cree que habría un defecto genético en el receptor de éste ligando como posible causa del cuadro ${ }^{(8)}$.

Siendo el engrosamiento de los pliegues gástricos una característica distintiva de la enfermedad de Ménétrier, este hallazgo no es específico de esta enfermedad. En el diagnóstico diferencial deben incluirse causas infecciosas como la infección por citomegalovirus, Helicobacter pylori e histoplamosis; causas inflamatorias como la enfermedad de Crohn, gastritis hipertrófica y gastritis postradiación; causas tumorales como el cáncer gástrico, el linfoma y el síndrome de Zollinger- Ellison; finalmente, causas infiltrativas como la amiloidosis, sarcoidosis y gastritis eosinofílica ${ }^{(1,2,6)}$. Algunos hallazgos que pueden ayudar en estrechar el diagnóstico diferencial son la distribución de los pliegues (compromiso de la curvatura menor favorece linfoma), la compresibilidad (rigidez apoya la malignidad), la pérdida de la estratificación de la pared (hallazgo propio de malignidad), la presencia de úlceras asociadas (característico del síndrome de ZollingerEllison) y otros hallazgos extragástricos (adenopatías y esplenomegalia sugieren linfoma) ${ }^{(1)}$.

El tratamiento médico con anticolinérgicos, prostaglandinas, prednisona o antihistamínicos $\mathrm{H} 2$ ha obtenido resultados variables. Los casos graves, con pérdida severa 
de proteínas o baja de peso importante son tratados con gastrectomía total ${ }^{(1,2)}$.

\section{Bibliografía}

1. Friedman J, Platnick J, Farruggia S, Khilko N, Mody K, Tyshkov M. Best Cases from the AFIP. Ménétrier Disease. RadioGraphics 2009; 29(1): 297-301.

2. Del Valle J. Úlcera péptica y trastornos relacionados. En: Kasper DL et al, editores. Harrison, Principios de Medicina Interna. 16a ed. McGraw-Hill 2005. Capítulo 274: 1924-1942.

3. Famularo G, Sajeva MR, Gasbarrone L. Beyond Gastritis and Before Cancer: The Strange case of Ménétrier disease. Intern Emerg Med 2011; 6(4): 369-371.

4. Burns B, Gay B. Menetrier's disease of the stomach in children. AJR 1968; 103: 300-306.
5. Tsurumaru D, Masunari S, Utsunomiya T, Takano H, Matsuura S, Nishihara Y, et al. Protein-Losing Gastropathy with hypertrophic gastric folds: Endosonographic Findings. J Clin Ultrasound 2008; 36(1): 35-38.

6. Palmer WE, Bloch SM, Chew FS. Ménétrier Disease. Radiologic-Pathologic Conferences of the Massachusetts General Hospital. AJR 1992; 158(1): 62.

7. Chen CY, Jaw TS, Wu DC, Kuo YT, Lee CH, Huang WT et al. MDCT of Giant Gastric Folds. Differential Diagnosis. AJR 2010; 195(5): 1124-1130.

8. Coffey RJ, Washington MK, Corless CL, Heinrich MC. Ménétrier Disease and Gastrointestinal Stromal Tumors: Hyperproliferative Disorders of the Stomach. J Clin Invest 2007; 117(1): 70-80.

de Grazia JA y cols. Enfermedad de Ménétrier. Rev Chil Radiol 2012; 18(2): 96, 140-142.

Correspondencia: Dr. José A. de Grazia / ja.degrazia@gmail.com 